\title{
LA PRODUCCIÓN E INSTRUMENTALIZACIÓN POLÍTICA DEL MIEDO EN LA CONCEPCIÓN CRISTIANA Y NACIONALISMO DE LA DECLARACIÓN DE PRINCIPIOS DE LA JUNTA DE GOBIERNO. CHILE, 1974 ${ }^{1}$
}

The political production and instrumentalisation of fear in the Christian and Nationalism Conception of the Declaration of Principles of the military Junta. Chile, 1974.

Freddy Timmermann*

Resumen

En el presente artículo se analiza la forma en que las elites del régimen cívico-militar, en la Declaración de Principios del Gobierno de Chile, generaron un dispositivo de poder discursivo para la producción e instrumentalización de miedo y angustia, en función de sus elementos trascendentes. Por medio del análisis historiográfico y crítico del discurso, y de teorías sobre el miedo y la angustia y sociología de las religiones, se vinculan sus componentes textuales con el contexto de poder en que se produjeron, incluyendo las ideologías, percepciones teológicas y míticas existentes, para establecer cómo se activa discursivamente la "concepción cristiana" y el "nacionalismo" para determinar sociopolíticamente los ritmos del miedo y angustia.

Palabras clave: Miedo, angustia, legitimación, violencia simbólica, seguridad.

Abstract

This article analyses how the civic-military regime's elite, in the Declaration of Declaration of the Government of Chile, generated a mechanism of discursive power to create and instill fear and anguish. Through an analysis of historical writings and a critical analysis of discourse and theories of fear and anguish and the sociology of religions, we link quotes with the context of power of that historical moment, including the ideologies and existing theological perceptions, to establish how discourse activates "christian ideology" and "nationalism" to bring about, sociopolitically, fear and anguish.

Key words: Fear, anguish, legitimacy, symbolical violence, security.

\section{INTRODUCCIÓN}

El presente estudio analiza la forma mediante la cual las elites del régimen cívico-militar proyectaron el miedo como dispositivo de poder

\footnotetext{
${ }^{1}$ Este artículo forma parte de la investigación realizada para el proyecto de iniciación Fondecyt N 11110460, "Miedo, Legitimación y Poder. Chile, 1973-1980”.
} 
discursivo a partir de los elementos trascendentes ${ }^{2}$ de la Declaración de Principios del Gobierno de Chile (en adelante, DP). El fundamento principal es comprender una de las formas en que un gobierno autoritario legitima su proyecto imponiendo, más allá del uso factual de la violencia física, el miedo en distintas intensidades, a partir de elementos discursivos vinculados a asunciones subyacentes simbólicas. El problema específico es determinar las macroformas discursivas mediante las cuales se proyectaron estos elementos de la DP para generar un dispositivo de poder generador de miedo y angustia, en función de la coyuntura de poder que les da origen. El objetivo general es analizar la forma en que se proyectan las macroformas textuales trascendentes de la DP como dispositivo de poder discursivo para generar e instrumentalizar el miedo, de acuerdo con las necesidades del contexto de poder por los que transita el régimen.

Se trabaja con el análisis crítico el discurso porque estudia el lenguaje como práctica social, considerando que el contexto de su uso es central para su comprensión, evitando establecer una relación determinista entre los textos y lo social en que los efectos del poder y de la ideología en la producción de sentido queden oscurecidos y se les considere como algo dado (Jäeger, 66-67). Se habla de un proceso temporal, de la existencia de "acontecimientos", "coyunturas" (Braudel, 24-27), "ideologías" y "mentalidades" (Vovelle, 12-18) que operan generando dinámicas históricas donde son construidos los dispositivos de poder (Revel, 36-38; Weber, 43) discursivos que activan el miedo. La legitimación estudiada (Van Dijk, Ideología. Una Aproximación..., 318327) lleva a precisar los procesos sutiles de persuasión o manipulación implicada, los movimientos de autorrepresentación positiva y presentación negativa de otros, y las hegemonías sobre los campos simbólicos e ideológicos en sus dimensiones temporales, vinculando la producción de miedo en función de elementos sagrados (Mongardini, 3450). Esto forma parte de la denominada "historia cultural" (Burke, 134-139), por cuanto este estudio se preocupa también por los aspectos simbólicos y su interpretación (Todorov, 9-23; 179-186) en cuanto efecto determinante del miedo y la angustia, con un punto de llegada en el ámbito político, y de los valores profesados por grupos particulares - las elites civiles y militares del o cercanas al gobierno del régimen cívicomilitar- en lugares particulares y períodos particulares, procurando precisar los componentes de una "cultura del miedo" centrados en prácticas y representaciones discursivas que evidencien inseguridad (Bauman, Miedo Líquido, 97-124; Robert, 9298; Brissett, 114-122).

\footnotetext{
${ }^{2}$ En la inmanencia, el ser queda circunscrito a, o mejor, inscrito en lo experimentable o finito, predicándose desde la vida, ya que su realización o ejercicio no pone al efecto como existente fuera de ella sino que significa autorrealización, donde el viviente es a la vez agente y paciente o sujeto actuado. Entenderemos por trascendencia las experiencias que sobrepasen los límites que señala la inmanencia (Pellegrino, 543-555).
} 
Se habla de miedo y angustia diferenciadamente. El miedo es instantáneo y se desarrolla en función de un objeto concreto, que puede o no ser sorpresivo en su aparición. La angustia es un efecto permanente de un miedo específico o de varios miedos, un estado psíquico más amplio en su extensión temporal, que permite esperar el peligro y prepararse para enfrentarlo. Puede prolongarse indefinidamente, en función de su producción en cuanto psicotecnología (Watson, 54-59). Se pueden instrumentalizar sus efectos (André, 21-33), instalar siempre un tipo de "imaginación" que lo origine antes de que su objeto generador se presente factualmente (Baumann, Miedo Líquido 9-35). Se coincide con Lira en considerar sus efectos como fenómeno individual, pero también social, en cuanto a "significación subjetiva y política" (Canetti, 299-309; Schwarz, 157-200). El miedo es un fenómeno psicofisiológico (Sofsky, 63-81) que puede contemplar en su origen, entre otros, elementos cognitivos de tipo ideológico, teológico o mítico, susceptibles de ser generados o modificados por medio de dispositivos de poder discursivos. Operan en esta aprehensión "universos simbólicos" (Berger-Luckmann, 120-134). Se toca el terreno del mito, porque existen enunciados que van más allá de la mera descripción de cosas, con imágenes que impulsan la voluntad a la acción, alimentadas de tradiciones verdaderas o legendarias que le dan su fuerza emocional. Se puede inventar o modificar (Hobsbawm) y, por ello, manipular, combatir con otro más rico en elementos afectivos (Flottes, 229-233). Opera desde una "célula explicativa", con una estructura básica similar, pese a que su contenido pueda variar (Lévy-Strauss, 62-63).

Los "acontecimientos" históricos relacionados con el "miedo" los identificamos por medio de una "gramática de texto" que da cuenta de las relaciones entre las oraciones de los textos enteros subyacentes a estas emisiones, las "palabras llenas" (Kerbrat-Orecchioni, 43-150). Luego se determinan el "tema" o "temas" trascendentes relacionados con la producción de "miedo", analizando "coherencias locales", "globales" y macroestructuras (Van Dijk, Estructuras y Funciones del Discurso, 9-19) en función de las "coyunturas" sociopolíticas existentes en el régimen cívico-militar entre fines de 1973 e inicios de 1974.

Si la modernidad es insegura para el fenómeno religioso católico oficial, el contexto existente desde el 11 de septiembre de 1973 planteó obstáculos que extremaban las urgencias vivenciales propiamente cristianas. Pero en la cultura laica la comprensión religiosa de la realidad sigue poseyendo una fuerza activa considerable, fundamentalmente por su carácter de religión de salvación, aunque predomina la creencia por sobre la fe (Cipriani, 298-301). Por ello, el discurso político, buscando establecer un "orden", a diferencia del discurso místico, trata de proveer una articulación estable entre plenitud política - el reverso de una situación de falta constitutiva, de dislocación y desestructuración social- y diferencia - de contenido positivo- (Laclau, 122-124. Habermas), en este caso, utilizando también estrategias para la producción de miedo y angustia, recogiendo "espacios ideológicos" en que su contenido, "verdadero o falso", es funcional respecto de alguna relación de dominación 
social de un modo no transparente (Zizeck, 15), y míticos, como el sueño de la Edad de Oro, la esperanza de la revolución mesiánica, la imagen de la Ciudad protectora, con funciones de animación creadora e incitación a la acción (Girardet, 172-176).

\section{LA CONCEPCIÓN CRISTIANA}

La DP permite establecer los desarrollos de los miedos existentes en las elites civiles y militares desde fines de 1973 hasta mediados de 1975, y otros anteriores, en una sociedad que ha perdido su consistencia política y producción de sentido (Timmermann, Violencia de Texto. Violencia de Contexto 93-136). En forma casi inmediata se transita desde una tendencia "restauradora" a una "fundacional" (Vergara, 17-27) y a una consolidación lenta de la hegemonía del poder personal de Pinochet, del Alto Mando del Ejército y de la Junta de Gobierno (Varas, 32-57). Desde 1974 el régimen comienza a legitimarse desde la trascendencia. Uno de estos desarrollos es procurar imponer una percepción vinculada a una percepción mesiánica del nuevo líder (Barros, 61-114; Timmermann, El Factor Pinochet 358-371). También se sistematiza la legitimación trascendente, realizándose una lectura de carácter tradicionalista e integrista de las nociones clásicas del pensamiento social católico, en particular, de persona humana, derechos naturales y Bien Común (CristiRuiz, 103-139; Vidal, 29-30; Brunner, 72-74).

La DP muestra constantemente palabras que evidencian la existencia de elementos trascendentes, de una sociedad insegura, con miedo, con antagonismos internos y actitudes defensivas (Timmermann, La Declaración de Principios... 338345, 481-482). La "concepción cristiana" opera en la inmanencia, pudiendo extraviarse pero también recuperarse (36). ${ }^{3}$ Se establece que "En consideración a la tradición patria y al pensamiento de la inmensa mayoría de nuestro pueblo, el gobierno de Chile respeta la concepción cristiana sobre el hombre y la sociedad" (13), que "dio forma a la civilización occidental" y que "es su progresiva pérdida o desfiguración la que ha provocado, en buena medida, el resquebrajamiento moral que hoy pone en peligro a esa misma civilización" (13). Se utiliza una percepción del pasado centrada en la "tradición Patria", la que está en riesgo, siendo la cercanía al Dios cristiano lo que protege al país. Se sostiene que es lo que "la inmensa mayoría", el "pueblo", desea (13). "De acuerdo con lo anterior" se expresa que "entendemos al hombre como un ser dotado de espiritualidad", lo que sirve para establecer un "fundamento" de "la dignidad de la persona humana", que esta se traduce en varias "consecuencias" inmanentes (13). En la primera se sostiene que "el hombre tiene derechos naturales anteriores y superiores al Estado, que "arrancan de la naturaleza misma del ser humano" al poseer un origen "en el propio Creador" (13). La palabra Estado aparece significando directamente el ejercicio de un amplio poder, aunque lo hace luego de dejar claro que este lo tiene la Junta y que ella se legitima en Dios (13). El orden jerárquico es Dios-Junta-Estado. El

\footnotetext{
${ }^{3}$ Citamos la DP poniendo entre paréntesis el número de página, luego de mencionar su contenido. 216
} 
poder del Estado es limitado, pues los derechos mencionados "no siendo él quien los concede, tampoco podría jamás negarlos", aunque "debe reconocerlos" y "reglamentarlos", lo que implica ponerlos en la historia según su poder, dejando latente la posibilidad de desconocerlos y de manipular la percepción de "espiritualidad". La segunda "consecuencia", el Estado debe estar al servicio de la persona y no al revés, es una redundancia más fundamentada que la anterior. Se expresa que el hombre "tiene prioridad" "desde el prisma del fin, porque mientras las sociedades o Estados se agotan en el tiempo y en la historia, el hombre los trasciende, ya que vive en la historia, pero no se agota en ella" (14). La tercera "consecuencia", el fin del Estado es el bien común general, complementa la legitimación del Estado. Define "bien común", que se expresa es "el fin del estado". Recurre para ello a la Junta, citando la "Declaración de la Junta sobre prescindencia política en la administración pública" de diciembre de 1973 (14), completando así la anterior construcción del orden Dios-Junta-Estado, constituyendo a la Junta en el vínculo entre Dios y el Estado, en el intermediario entre lo trascendente e inmanente.

Se resaltan los atributos básicos que deben rodear al "bien común": un equilibrio entre el individualismo y la solidaridad social y la consideración de "los derechos naturales de la persona humana" (15). El hombre es percibido como individuo cuando se define "el bien común general", precisando que alcanza "a cada uno de los chilenos" (14), pero pensando en "las condiciones sociales" que permitan "alcanzar" una "plena realización personal" (14-15). El individuo que aparece en "el individualismo liberal" (15), en términos económicos en cuanto al "consumo" (10), no es bien visto pues allí el "bien individual" se trata de obtener "con la total prescindencia del de los demás" (14-15). También, porque el "materialismo" "corroe" a las llamadas "sociedades de consumo", denunciándose la existencia de un bienestar que "más que ayudar a la perfección integral del hombre lo someta a una carrera que lo domina, en pos de una riqueza que al final deja vacío su espíritu. Que más que liberarlo lo esclaviza" (10-36). Indirectamente se pone en manos del Estado el reconocimiento de los derechos naturales del hombre, pero, más adelante, ya en el terreno inmanente de la economía, siempre con la base trascendente mencionada, no se permite —en la cuarta consecuencia, el bien común exige respetar el principio de subsidiariedad - que perturbe al "individuo liberal" al expresar que este debe poseer "un ámbito de vida y actividad propia independiente", "solo [siendo] sometido al superior control de este [el Estado] desde el ángulo del bien común, donde reside la fuente de una vida social en que la libertad ofrezca a la creación y al esfuerzo personal un margen de alternativas y variedad suficientes" (17-18). Después de ello se trata la quinta consecuencia, el respeto al derecho de subsidiariedad supone la aceptación del derecho de propiedad privada y de la libre iniciativa en el campo económico (1820 ), donde se afirma que no se admite "otra fuente de desigualdades entre los seres humanos que las que provengan del Creador o del mayor mérito de cada cual" (24), pues no se "excluye" el "sano espíritu de competencia entre los que desarrollan una 
misma tarea", sino que esto se debe "fomentar" "como un valioso instrumento de empuje colectivo" (24-25-34).

El individuo perfilado está enmarcado por una noción de trascendencia que lo obliga, en función de cumplir una virtud en la que está implícita la pervivencia hacia una vida proyectada más allá de la histórica, y por una noción de inmanencia - política, económica - que recoge lo anterior, imponiendo determinados límites, siendo el Estado quien se encarga de velar por su cumplimiento en los aspectos políticos y la conciencia de cada uno en lo económico.

\section{LA TRADICIÓN NACIONALISTA}

Se afirma que el "nacionalismo" es "expresión genuina del ser de la patria y del alma de su pueblo" (23), "constante" de "nuestra historia" que "forma" el "acervo de nuestra tradición", es decir, un elemento que se vincula a la inmanencia en función de un pasado que es conservado como "tradición" (21). El "objetivo fundamental" de la "Junta" es el logro de la "unidad nacional" para "hacer de Chile una gran nación" (21), sustentar una "reoriginación a partir de las entrañas mismas del alma nacional" $(36,37)$, lo que se conseguirá con la "integración espiritual del país" (22), siguiendo los "valores fundamentales" de esta (23). En el "Prólogo", "patria" se vincula a una historia que entra en una "nueva era" generada desde "La Junta de Gobierno", por el "nuevo gobierno de unidad nacional que encabezan las Fuerzas Armadas y de Orden" (9). Ambos se confunden con la "patria" al expresar que esta "ha decidido combatir frontalmente en contra del comunismo internacional y la ideología marxista que este sustenta, infligiéndole su más grave derrota de los últimos treinta años" (10). La "patria" es "ella", es femenina, es quien guía el camino, quien lucha y triunfa. Así, la Junta de Gobierno y las Fuerzas Armadas y de Orden se proyectan como la "madre patria" que "busca" el camino extraviado de "Chile"en forma "propia y original" (10-11).

La percepción de "Chile" (portada, 28) significa básicamente "país", aunque posteriormente posee matices diferentes, pues el autor habla indistintamente de "nación", "patria", "pueblo", "república" sin diferenciarlos con precisión, aunque los expone interactuando como un ser vivo, con "cuerpo" y "alma". Desde el pasado se le atribuye "una larga tradición de organización social, que se remonta a su origen hispánico" (30) y se le caracteriza como económicamente "subdesarrollado" (9), pero en el presente está "inserto" en el "mundo contemporáneo" (21), siendo su realización "una tarea colectiva" (24), "la tarea de Chile" (38), siempre inconclusa. "Chile" es un ser vivo que "rechaza" una sociedad de inspiración marxista (9), que tiene experiencia respecto del comunismo - "viene de vuelta" (10) - , que debe alcanzar "la libertad" (11). Para el futuro, su trabajo es "tratar" de convertirse en una "nación de propietarios y no de proletarios" (19), en "una gran nación" (21-22), en un país "grande y unido" (22). Pretende "afianzar en todos los campos la dignidad nacional, restituyéndole a nuestro país el prestigio mundial que tradicionalmente tuvo y que el gobierno marxista debilitara en importantes aspectos" (37). Es un vocablo que reúne 
la percepción de "nacionalidad", cuya DP debe conocer "cada chileno" para tener una "participación activa" en la "reconstrucción nacional" (Prólogo). Debe lograrse una "integración espiritual" que le "reivindique" y "siembre" "en el corazón [del "chileno"]... el ejemplo de nuestra historia patria, con sus próceres, héroes, maestros y estadistas" (22). De él se espera "la aceptación de su cuota personal y familiar en el indispensable sacrificio colectivo" (25). El autor une la palabra "gobierno" a otras, buscando significados concretos (de la Junta, de las Fuerzas Armadas, de Chile o nacionalista). Quienes poseen la fuerza son las "Fuerzas Armadas y de Orden". La "Junta", que las controla, ejerce el poder con un proyecto que va más allá del uso de la fuerza, de la plena inmanencia en que opera. El orden establecido es: Dios-PatriaMadre-Junta-Gobierno. La "patria" adquiere así un carácter trascendente proyectado fuera de la historia y que es necesario preservar para recuperar la "tradición". A la luz de lo antes expresado, este deber político se convierte en una cruzada religiosa.

\section{LA NACIÓN EXTRAVIADA}

El gobierno "reconoce y proclama" los "valores fundamentales del alma nacional" (23). El "nacionalismo" es presentado como "un estilo de conducta" (23) que busca precisar un marco de acción cristiano con consecuencias directas en el quehacer político, económico y social. Se apela a su supuesta existencia, la que, extraviada en la época de la Unidad Popular, debe nuevamente reaparecer (21-22).

Los valores se incluyen en las "conclusiones", que se "desprenden" de la "búsqueda" por parte de la Junta de Gobierno, en la "realidad chilena", de "elementos que complementen su visión filosófica y doctrinaria". Para ello se "conjugan" "las constantes de nuestra historia que forman el acervo de nuestra tradición, con las características nuevas que hemos visto surgir en el último tiempo" (21). Es decir, a las anteriores "consecuencias" de la "espiritualidad" que se derivan de la "concepción cristiana" se suman las "conclusiones", que se derivan del "nacionalismo". En la quinta "conclusión", Un orden jurídico respetuoso de los derechos humanos: marco para el actual gobierno, se afirma que la "unidad nacional" se alcanzará no por medio de la anterior democracia — desde una "tradición de generación popular y sucesión constitucional de gobiernos" (26)-, sino por medio de un sentimiento que viene del pasado y que forma parte del nacionalismo, que el autor antes ha derivado de la "concepción cristiana", es decir, de Dios. Conspiran" en contra de esa "unidad nacional extraviada" "las ideologías foráneas", "el sectarismo partidista", "el egoísmo o antagonismo deliberado entre las clases sociales" y "la invasión cultural extranjerizante" (22). Se insistirá a lo largo del texto en que la realidad fundamental de la "nación" es la "reconstrucción" (9), pero no en la dirección alcanzada por las naciones "más avanzadas de Occidente" (9-10), sino siguiendo "un camino... propio y original" que "trate de superar los distintos factores de crisis que hoy sacuden a otras naciones" (11). Vemos, por lo tanto, que se establece la misma dependencia que 
con la "patria", pues la "nación" debe "reconstruirse" del daño causado por el marxismo, tarea que depende del gobierno.

La novena "conclusión" se refiere a La familia, la mujer y la juventud: pilares de la reconstrucción nacional (38). Se expresa que "la familia [es] su más sólido fundamento como escuela de formación moral, de entrega y generosidad hacia los semejantes y de acendrado amor a la Patria" (38). Menciona siempre a la familia como base social, no al individuo (30). "La mujer" "se realza en toda la grandeza de su misión, que la convierte en la roca espiritual de la Patria" (38). En ella radica una suerte de absoluto trascendental que garantiza la conservación "espiritual" de esta en la historia. La "formación moral", la "entrega y generosidad hacia los semejantes" forman parte de "la grandeza de su misión". Opera en función de un "coraje", junto a la "juventud", desde antes del golpe cívico-militar en la protección de la "Patria", pues lo "demostraron en los últimos años, como baluartes del movimiento cívico que culminara con el pronunciamiento militar del 11 de septiembre" (38). Este "coraje", que es un atributo "espiritual" de la "patria" "debe ahora convertirse en fibra patriótica para afrontar el duro sacrificio que nos espera por delante, y en fuerza creadora para transformar en realidad una honda esperanza nacional" (38).

Las anteriores legitimaciones que vinculaban a Dios con el Padre inmanente, la Junta de Gobierno, suman en el vínculo a la Madre trascendente, la Patria. La Junta es Madre y Padre al mismo tiempo, pero la proyección, más que a un plano político amplio como se hizo con la imagen del Padre, es, al introducir la familia, a un plano cotidiano, a la que guían.

\section{CONCLUSIONES}

La DP establece un proceso de des-secularización al posibilitar el resurgimiento de elementos sagrados, proyectados sin instituciones y organizaciones religiosas reguladoras, estableciendo un vínculo entre moralidad pública y privada, repolitizando la esfera moral y religiosa privada, pero también la pública, otorgando una legitimación trascendente al régimen cívico-militar, independiente de la Iglesia católica del cardenal Silva Henríquez y de la Conferencia Episcopal de Chile. Al concebirse al hombre como "un ser dotado de espiritualidad", la posibilidad concreta de que se profundice la pérdida de un absoluto trascendente como la "concepción cristiana" o la "tradición" "patria" o "nacionalista" articula los elementos que producen el miedo y la angustia en la DP, pues se introduce discursivamente inseguridad. La proyección inmanente de las "consecuencias" que se derivan de esta concepción del hombre, suma al desarrollo metahistórico el propiamente histórico, ligado a la sociopolítica y economía, al generar un disciplinamiento que se debe traducir en obediencia. El orden jerárquico que establece la DP es Dios-Junta de Gobierno-Estado, siendo la Junta intérprete de la verdad divina y de la tradición. Se tiende a alcanzar el "bien común" como individuo respetando la solidaridad social, que en realidad es sociopolítica, bajo el control del Estado, que para cautelar su cumplimiento puede recurrir al uso de la violencia, la "sanción drástica" (23) si es 
necesario. Pero debe respetar en el individuo el "principio de subsidiariedad", que supone el derecho de propiedad privada y de libre iniciativa en el campo económico. Por ello, los miedos, su producción, proyectarán una actividad política sustentada en legitimaciones trascendentes que vinculen el poder inmediato de la Junta de Gobierno con castigos para los "pecadores" que vulneren la concepción cristiana y para los "traidores" que lo hagan con el nacionalismo; uno en el tiempo más allá de la historia y el otro en el tiempo inmediato, por medio de la "sanción drástica". La actividad económica proyecta solo el temor a que Chile sea subdesarrollado y pobre (33-34). El principal miedo de las elites del régimen cívico-militar es que la "nación" no alcance la "unidad" en función del disciplinamiento sociopolítico mencionado, es decir, que exista una regresión hacia el marxismo que impida una "reoriginación" del "alma nacional". La constante mención de esta posibilidad, de esta pérdida, es otra de las formas en que la DP introduce inseguridad para la instalación del miedo. Su vinculación con la Junta sustenta esta dependencia, pues esta se confunde con la "patria", por un lado, y es quien dirige a las Fuerzas Armadas y de Orden, por otro. Guía al gobierno de Chile, al "país", al "pueblo", a la "nación", al "chileno". Es decir, la Junta puede operar en función de una violencia factual pero también simbólica, pues el "pueblo" en su deber hacia la "patria" está inmerso en una cruzada religiosa en que los "valores" del "nacionalismo" le imponen actuar.

La "unidad nacional" se logrará no por medio de la anterior democracia liberal, sino sustentada en la "concepción cristiana" y "nacionalismo". La producción de miedo se dirige directamente enfocada hacia quienes la amenazan: "Occidente", "las ideologías foráneas", "el sectarismo partidista", la "invasión cultural extranjerizante" y el "egoísmo o antagonismo deliberado entre las clases sociales". Así, la "nación" se "reconstruye" en el tiempo inmediato, por los efectos que el miedo genera sobre el necesario disciplinamiento sociopolítico que ello necesita, pero también en el tiempo mediato, si se piensa que permite individual y colectivamente paralizar la absorción de cambio sociopolítico y, con ello, la marcha de la historia. Al mismo tiempo, esto último es fortalecido desde una dimensión más restringida, que también opera en la producción de miedo en un tiempo de más largo plazo, la familia. Se resalta el papel de la mujer al respecto, la "roca espiritual de la patria", poseedora de un "coraje" en el pasado y "fibra patriótica" en el presente y futuro. Los miedos en un nivel básico, propio, privado, como es el ámbito familiar, son producidos y/o disciplinados en una instancia social no cuestionada y legitimada por Dios y el Estado. Con ello, las estructuras que potencian o mantienen las dependencias vinculadas a él antes referidas se prolongan en el tiempo, reproduciéndose. Existe, además, una proyección aun menor de la producción de miedo, una que contempla al cuerpo, constituyéndose en biopolítica, si se considera que los dispositivos de poder discursivos mencionados generan reacciones psicofisiológicas funcionales a este.

La DP proyecta sus dispositivos de poder discursivos ligados a elementos trascendentes produciendo o guiando la transformación del "deos" en "phobos", del 
miedo reflexivo y mental, controlado, a uno intenso e irracional, acompañado de una huida, la que se direcciona en función del disciplinamiento sociopolítico mencionado. Se desea instrumentalizar la "huida", instalar si es necesario un tipo de "imaginación" que origine un miedo antes de que este se presente factualmente, antes de que nada suceda. Es el tránsito de los miedos al presente - porque estos no actúan solo en el sentido negativo sino también en el sentido de la socialización, como las restantes emociones - y de la angustia al presente-futuro, mantenida siempre como huida posible. Es a partir de ello que las elites civiles y militares, produciendo ambos, se presentan como otorgadoras de protección y seguridad, debido a que se reapropian de la realidad por medio de su interpretación. Para ello también, sin embargo, concurren elementos extradiscursivos, pues instauran el "terror" para imponerla por medio de la "sanción drástica" y de violencia simbólica desplegada al controlar totalmente los medios de información societal, lo que se comprende porque el terror no existe solamente durante la aplicación de la violencia sino cuando esta no se emplea y se cierne como un peligro constante. Su atmósfera es la amenaza y en esta la vida del hombre está más afectada que durante la acción efectiva del terror. Con ello, las elites generan miedo a la sociedad, pero también se angustian a sí mismas, obligándose a producir miedo para superarlo.

En esta vida plasmada por el terror, miedo y cultura, emoción y razón, se constituyen en un equilibrio inestable, porque el exceso de una reactiva la otra. En una cultura cerrada como la autoritaria estudiada, con severos controles de cualquier disenso, este hecho se acentúa aún más, generándose una autorreproducción del miedo. La dinámica religiosa se desplaza desde un acento puesto en la relación afectiva con Dios - en cuanto a fuente de realización de la persona y enriquecimiento de las relaciones con los demás-, a una vivencia de un catolicismo como humanismo trascendente que pone en juego una concepción ético-afectiva de la salvación y de dominación intramundana individualista. Es un nuevo compromiso psicológico entre el cristianismo y una modernidad que se muestra bajo un rostro autoritario, con el ejercicio de una violencia factual brutal, imponiendo una experiencia de miedo y angustia desconocidas, que exige una estrategia de sobrevivencia urgente centrada en una "memoria colectiva autorizada", que se expresa por medio de la DP. Es la proyección del acto de creer más que de fe, pues se incluyen junto a los ideales de convicción las prácticas, los lenguajes, los gestos, los automatismos espontáneos con los que estas se manifiestan. Se piensa en cuidarse, no en salvar el alma. Es la fe en acto, permeada por elementos de una coyuntura de una sociedad en una profunda crisis de sentido, de una sociedad con miedo y angustia que busca sobrevivir.

Universidad Católica Silva Henríquez* Escuela de Educación en Historia y Geografia General Jofré 462, Santiago Centro (Chile) ftimmer@ucsh.cl 
La producción e instrumentalización política del miedo en la concepción cristiana

\section{OBRAS CITADAS}

Junta Militar de Gobierno. Declaración de Principios del Gobierno de Chile. Santiago: Gabriela Mistral, 1974.

André, Christophe. Psicología del Miedo. Barcelona: Kairos, 2005.

Barros, Robert. La Junta Militar. Pinochet y la Constitución de 1980. Santiago:

Sudamericana, 2005.

Bauman, Zygmunt. Miedo Líquido. Buenos Aires: Paidós, 2007.

Berger, Peter-Luckmann, Thomas. La Construcción Social de la Realidad. Buenos Aires: Amorrortu, 1989.

Braudel, Fernand. Las Ambiciones de la Historia. Barcelona: Crítica, 2002.

Brissett, Wilson. "Ensayo bibliográfico sobre el miedo", en The Hedgehog Review, 2003 3, vol. V, 115-123.

Brunner, Joaquín. La Cultura Autoritaria en Chile. Santiago: FLACSO, 1981.

Burke, Peter. ¿Qué es la Historia Cultural? Barcelona: Paidós, 2006.

Canetti, Elías. Masa y Poder. Madrid: Alianza Editorial, 1995.

Cipriani, Roberto. Manual de sociología de la religión. Buenos Aires: Siglo Veintiuno, 2011.

Cristi, Renato. El Pensamiento Político de Jaime Guzmán. Santiago: LOM, 2000.

Flotes, Pierre. El Inconsciente en la Historia. Madrid: Guadarrama, 1971.

Girardet, Raoul. Mitos y mitologías políticas. Buenos Aires: Nueva Visión, 1996.

Habermas, Jurgen. Teoría de la acción comunicativa. II. Madrid: Taurus, 1999.

Hobsbawm, Eric. La Invención de la Tradición. Barcelona: Crítica, 2002.

Jäger, Sigfried. "Discurso y conocimiento: aspectos teóricos y metodológicos de la crítica del discurso y del análisis de dispositivos", en Wodak, Ruth. Métodos de Análisis Crítico del Discurso. Barcelona: Gedisa, 2003.

Kerbrat-Orecchioni, Catherine. La enunciación de la subjetividad en el lenguaje. Buenos Aires: Edicial, 1997.

Laclau, Ernesto. Misticismo, retórica y política. Buenos Aires: F. C. E., 2006.

Lévy-Strauss, Claude. Mito y Significado. Madrid: Alianza Editorial, 1995.

Lira, Elizabeth-Castillo, María. Psicología de la Amenaza Política y del Miedo.

Santiago: ILAS, 1991.

Mongardini, Carlo. Miedo y Sociedad. Madrid: Alianza Editorial, 2007.

Pellegrino, Urs. Diccionario Teológico Interdisciplinar. Tomo IV, Salamanca: Sígueme, 1983.

Revel, Judith. El vocabulario de Foucault. Buenos Aires: 2008.

Robert, Philippe. "Seguridad objetiva y seguridad subjetiva", en Revista Catalana de Seguretat Pública 16, 91-102, Barcelona, 2006. 
Schwartz, Urs. "La Angustia en política", en Hediger, Heini et al. Tribuna de la Revista de Occidente. Madrid: Revista de Occidente S.A, 1960.

Sofsky, Wolfgang. Tratado sobre la violencia. Madrid: Abada, 2006.

Timmermann, Freddy. La Declaración de Principios de la Junta Militar. Chile, 1973-1980.

Tesis Doctoral, Santiago: Universidad de Chile, 2009.

------- Violencia de Texto. Violencia de Contexto. Historiografía y Literatura Testimonial. Chile, 1973. Santiago: Ediciones Universidad Católica Silva Henríquez-Centro de Investigaciones Barros Arana, 2008.

------ El Factor Pinochet. Dispositivos de poder, Legitimación, Elites. Chile, 1973-1980. Santiago: Ediciones Universidad Católica Silva Henríquez, 2005.

Todorov, Tzvetan. Simbolismo e Interpretación. Caracas: Monte Ávila Editores, 1992.

Van Dijk, Teun. Ideología. Una Aproximación Multidisciplinaria. Barcelona: Gedisa, 1999.

------- Estructuras y Funciones del Discurso. Ciudad de México: Siglo Veintiuno, 1997.

Varas, Augusto. Los Militares en el Poder. Régimen y Gobierno Militar en Chile 1973-1986. Santiago: Pehuén-FLACSO, 1987.

Vergara, Pilar. Auge y Caída del Neoliberalismo en Chile. Santiago: FLACSO, 1985.

Vidal, Hernán. Chile: poética de la tortura política. Santiago, Mosquito, 2000.

Vovelle, Michel. Ideologías y Mentalidades. Madrid: Ariel, S.A., 1985.

Watson, Peter. Guerra, persona y destrucción. Usos militares de la psiquiatría y la psicología. Ciudad de México: Nueva Imagen, 1982.

Weber, Max. Economía y Sociedad. Bogotá: F. C. E., 1997.

Zizek, Slavoj. "El Espectro de la Ideología", en Zizek, S. Ideología. Un mapa de la cuestión. Buenos Aires: F.C.E., 2008. 